\section{Cleaning up after Chernobyl}

SIR-Confusion still exists regarding the actions that might have been appropriate in the immediate aftermath of the passage of the Chernobyl fall-out cloud over the United Kingdom. Initial reports ${ }^{1}$ of the environmental levels and numbers of people exposed to them upon, on which I based an early assessment of the impact on health of the accident ${ }^{2}$ have been revised (J. Simmonds and M. J. Crick, article submitted to Nature in March 1987 and subsequently withdrawn) following an $\operatorname{article}^{3}$ and correspondence ${ }^{4}$ in the National Press.

Based on the revised values for iodine131 in milk, I now estimate the average dose to the thyroids of 6-month-old children (the members of the population expected to receive the highest doses from any given level of contamination) drinking fresh cow's milk in the high rainfall areas to have been about $5 \mathrm{mGy}$ (assuming 0.5 litres per day milk consumption), rather than 10-20 mGy (ref. 2). A value of $5 \mathrm{mGy}$ corresponds to about a 10 per cent increase in the spontaneous risk of the largely nonfatal thyroid cancer for those children ${ }^{2}$.

But the measurements reported by the NRPB (National Radiological Protection Board) are described as 'representative'; more recent measurements of caesium137 on the ground made by aerial survey in Scotland showed local fluctuations of an order of magnitude or more ${ }^{5}$ and cast serious doubt on the validity of deposition estimates based on earlier monitoring and predictions in some upland zones ${ }^{6}$. The possibility that levels of iodine on some pasture might have been 10 or more times higher, and therefore that some local milk supplies might have been more heavily contaminated than the revised NRPB results indicate, cannot now be excluded.

The decision? not to take countermeasures to limit iodine-131 consumption was based on the criteria for limiting exposures of the public in the event of an accidental release of radioactivity, the so-called Emergency Reference Levels ${ }^{8}$. These ERLs are designed to protect individuals from excessive exposure in the early stages of accidents occurring in Britain, and are therefore usually envisaged as being only temporarily applicable to local populations in the vicinity of the accident. Very careful consideration should be given to their extension to the situation where the whole country might be affected and the rapid and comprehensive monitoring of fall-out levels is demonstrably not feasible.

The annual effective dose equivalent limit for members of the public is $1 \mathrm{mSv}$ (ref. 9), whereas the lower ERL of dose applicable to the thyroid is $50 \mathrm{mSv}$ (ref. 8 ). Thus, after the accident some children will have received about a sixth of the annual dose limit from iodine alone and in greater.

some cases possibly an ERL or more of dose to the thyroid (in this case Sv and Gy are numerically identical). Doses from other sources, including external exposure, could also have been correspondingly

In the case of the short-lived isotopes of iodine it is doubtful whether, in the circumstances of widespread fall-out following the accident, the situation could ever be assessed in time to take effective action, and pre-emptive action, based on early air monitoring data, would be appropriate. The removal of cattle from pasture in the Netherlands for 4 days following the first indication of iodine- 131 in milk is reported by NRPB to have saved about 50 per cent of dose to the critical group $^{10}$. Experience indicates that, following a release of radioactivity from an operating reactor, the short-lived isotopes of iodine will dictate the immediate response. This response, as advised by the

\section{Early warning for LTP}

SIR-Davies et al. ${ }^{1}$ recently reported that the induction of long-term potentiation (LTP) is associated with an increase in the sensitivity of hippocampal CA1 neurons to L-glutamate analogues. The increased sensitivity was slow to develop, being first observed 15-30 min after LTP induction, and reaching a peak only after 1-2 hours. The authors interpreted their results as evidence for a presynaptic component mediating the early phase of LTP maintenance. However, postsynaptic sensitivity was assessed in their experiments by monitoring the amplitude of quisqualate $(\mathrm{Q})$ and AMPA ( $\alpha$-amino-3hydroxy-5-methyl-4-isoxazole proprionic acid) potentials which had a very slow time course (compared with the excitatory postsynaptic potentials) and which were generated by very large iontophoretic ejection currents $(\mathrm{Q}, 46-163 \mathrm{nA}$ for 1-2 s; AMPA, 40-155 nA for 10-25 s). One possibility that should be considered is that the application of such large and prolonged doses of $\mathrm{Q}$ and AMPA induced desensitization of the synaptic $Q$ receptors and consequently, the slow iontophoretic responses monitored in the study of Davies et al. ${ }^{1}$ may have been generated by activation of extrasynaptic receptors. Recent studies have shown that quisqualate and AMPA activate two types of receptors, one rapidly activating and rapidly desensitizing, and the other slowly activating and maintained.

The rapidly activating and desensitizing responses were found in clusters or hot spots, and were suggested to be caused by activation of synaptically lo-
NRPB $^{8,11}$, should be based on optimization or on the principle that doses are kept as low as is reasonably achievable, rather than dose limits.

\section{K. F. BAVERSTOCK}

MRC Radiobiology Unit,

Chilton, Didcot

OxOn OX11 ORD, UK

1. Fry, F.A., Clarke, R.H. \& O'Riordan, M.C. Nature 321 193-195 (1986).

2. Baverstock, K.F. Int. J. Radiat. Biol. 50 i-xiii (1986); correction, 51, 184 (1987)

3. Ferriman, A. \& McKie, R. Observer 21 September (1986).

4. Dunster, H.J. Observer 28 September (1986).

5. Prosbaig broadcast on BBC Scotland Channel 2, 22 March 1988.

6. 'Scottish Eye' broadcast on Channel 4, 28 January 1989 . House of Commons Agricultural Committee, 2nd Report. Vol. 1, (HMSO, London 1988)

8. National Radiological Protection Board Publ. ERL2 (HMSO, London, 1981)

9. National Radiological Protection Board Publ. GS4 (HMSO, London, 1986).

10. Morrey, M. et al. CEC Report EUR 11523 (1988)

11. Clarke, R.H. Radiological Protection Bull. No. 88 (1988)

This letter is a revised version of one submitted after the Chernobyl accident in April, 1986.

Editor, Nature

cated receptors, whereas the slowly activating non-desensitizing responses were evenly distributed, and are probably extrasynaptic receptors ${ }^{2.3}$. If the responses monitored in the study of Davies et al. were caused by the activation of extrasynaptic Q receptors, then their location or properties may render them less rapidly responsive to the LTP inducing signal than the synaptic receptors. Thus, early changes in $Q$ synaptic sensitivity following LTP induction may not have been observed.

The time taken to establish an increase in $\mathrm{Q}$ postsynaptic sensitivity is important in elucidating the different components of LTP. Thus recent studies have demonstrated that the initial component of LTP is an NMDA receptor induced short-term potentiation (STP), which peaks at 3-5 min and has an overall time course of 10-30 $\mathrm{min}^{4}$. If an increase in post-synaptic receptor sensitivity were to occur earlier following the tetanus than that observed by Davies et al. ${ }^{1}$, then the establishment of LTP could be explained by the initial NMDA induced STP followed immediately by a postsynaptic increase in receptor sensitivity.

Faculty of Health Sciences,

R. ANWYL

Department of Physiology,

Trinity College,

Dublin 2 ,

Ireland

\footnotetext{
1. Davies, S.N., Lester, R.A., Reymann, K.G. \& Collingridge, G.L. Nature 338, 500-503 (1989).

2. Tang, C.-M., Dichter, M. \& Monrad, M. Science 243 , 1474-1477 (1989)

3. Trusell, L.O., Thio, L.L., Zorumski, C.T. \& Fischback G.D. Proc. natn. Acad. Sci. U.S.A. 85, 2834-2838 (1988).

4. Kauer, J.A., Malenka, R.C. \& Nicoll, R.A. Nature 334
} 250-252 (1988) 